\title{
Can Tourism Climatic Indices Reflect the Impact of Cold Surges?
}

\author{
Yan Dong ${ }^{\mathrm{AB}}$, Lan Xia ${ }^{\mathrm{AC}}$ * \\ Received: June 25, 2021 | Revised: October 01, 2021 | Accepted: November 03, 2021 \\ doi: 10.5937/gp25-32853
}

\begin{abstract}
Hibernation tourism in East and Southeast Asia is directly impacted by wintertime cold surges, which can result in high winds, extreme low temperatures, frost, freezing rain, and even sandstorms. This study compares two existing tourism climatic indexes-the Comprehensive Comfort Index (CCI) and the Tourism Climate Index ( $\mathrm{TCl}$ - - to establish their ability to capture the full impact of cold surges on the tourism industry. From a climatic perspective, the $\mathrm{TCl}$ is more sensitive than the $\mathrm{CCl}$, revealing a significant negative correlation with cold surge days. As illustrated here using a specific case study, the colder surge days in a month, the lower the $\mathrm{TCl}$ score for that month. This paper also evaluates potential reasons for the observed disparity between the two indices and proposes that the $\mathrm{TCl}$ exhibits a higher temperature standard and preference for long sunshine hours than does the $\mathrm{CCl}$.
\end{abstract}

Keywords: Tourism Climate Index; Cold surge; Climate comfort; Hibernation tourism

\section{Introduction}

Hibernation tourism, also known as cold avoidance tourism, has become an important industry sector in recent decades (Feng et al., 2010). This is particularly true for older generations, who commonly migrate to warmer, more comfortable environments during the winter months to reduce the risk of seasonal health problems. Despite its popularity, however, hibernation tourism is not invulnerable to cold surges, which are anomalous meteorological events (Chang et al., 2011) characterized by strong northerly winds and depressed surface air temperatures (Pang \& Lu, 2019). Cold surges have also been linked to the intensification of atmospheric convection and amplified rainfall and flooding (Pullen et al., 2015). Ultimately, the clear risks posed to outdoor activities by cold surges warrant a more nuanced understanding of how these meteorological events impact hibernation tourism.
Researchers seeking to investigate climatic comfort quantitatively and objectively can now draw from a large number of indices, factors, and scores developed specifically for this purpose. In this study, we pose the question: Do existing tourism climatic indices fully reflect the impact of cold surges? To address this question, we compared the output of two current indices. First proposed by Mieczkowski (1985), the Tourism Climate Index (TCI) has since been applied widely (Scott et al., 2004; Shi, 2016) and is also used as the foundation for more recent indices, including the Climate Index for Tourism (CIT; de Freitas et al., 2004), the Modified Climate Index for Tourism (MCIT; Yu et al., 2009), and the Holiday Climate Index (HCI; Scott et al., 2016), among others. We compared the TCI with the Comprehensive Comfort Index (CCI; Ma et al., 2009), which is a composite of the Temperature and Humidity Index (THI; Thom, 1959),

\footnotetext{
A School of Earth Sciences, Yunnan University, Chenggong University Town, 650500, Kunming, Yunnan, People's Republic of China.

B Meteorological Bureau of Suijiang County, 65770, Zhaotong, Yunnan, People's Republic of China

c Key Laboratory of Atmospheric Environment and Processes in the Boundary Layer over the Low-Latitude Plateau Region, Department of Atmospheric Sciences, Yunnan University, Kunming

* Corresponding author: Lan Xia; e-mail: lanxia@ynu.edu.cn
} 
the Wind Effect Index (WEI; Terjung, 1966), and the Clothing Index (ICL; de Freitas, 1979), which has been used extensively to analyze the comfort of summer and winter climates (Yu et al., 2018; Luo et al., 2017; and Deng et al., 2020).

Popular Chinese destinations for hibernation tourism include Hainan and Yunnan Provinces (Lin et al., 2019). In one recent study, Lin et al. (2013) investigated the number of climate comfortable days during the winter months (November to April) in 11 tourist cities; they reported that Sanya and Haikou on Hainan both experience 181 days with temperatures of $>16^{\circ} \mathrm{C}$, while Jinghong in Yunnan experiences 145 days $>16^{\circ} \mathrm{C}$. Lin et al. (2013) also observed that Sanya (Jinghong) experiences a total of 585 (543.6) sun- shine hours in winter. Considering both local climate conditions and environmental pollution, comfortable periods are generally longest in Sanya, Hainan, and second longest in Kunming, Yunnan (Zhang and Han, 2020). Because both provinces are located at low latitude, and thus characterized by mild winter climate conditions (Deng \& Bao, 2020), we employed Hainan and Yunnan as example locations in the present paper. Specifically, we applied the CCI and TCI to assess winter climate comfort for hibernation tourism in both provinces, before comparing the capacity of each index to reflect the impact of cold surges. In doing so, our overarching objectives are to improve our understanding of both indices and provide a nuanced view of how extreme weather impacts tourism.

\section{Data and methods}

\section{Data}

For this investigation, we employed basic daily meteorological variables (e.g., air temperature, relative humidity, surface wind speed, and sunshine hours) recorded by base stations operated by the China Meteorological Administration between 1981 and 2010 . Our specific temporal focus is the winter months (DJF: December, January, and February) and all data have been evaluated for quality control. For homogeneity and validation purposes, we have excluded those stations with records spanning $<30$ years, with the result that our analysis is based on a total of 27 stations in Yunnan Province and seven on Hainan (Fig. 1). Located in southwest China, Yunnan Province is characterized by mountainous and plateau topography. Climatically, winters are mild due to the blocking of cold air currents by the Tibetan Plateau to the northwest, and summers are relatively cool due to the region's generally high elevation. Between May and October,
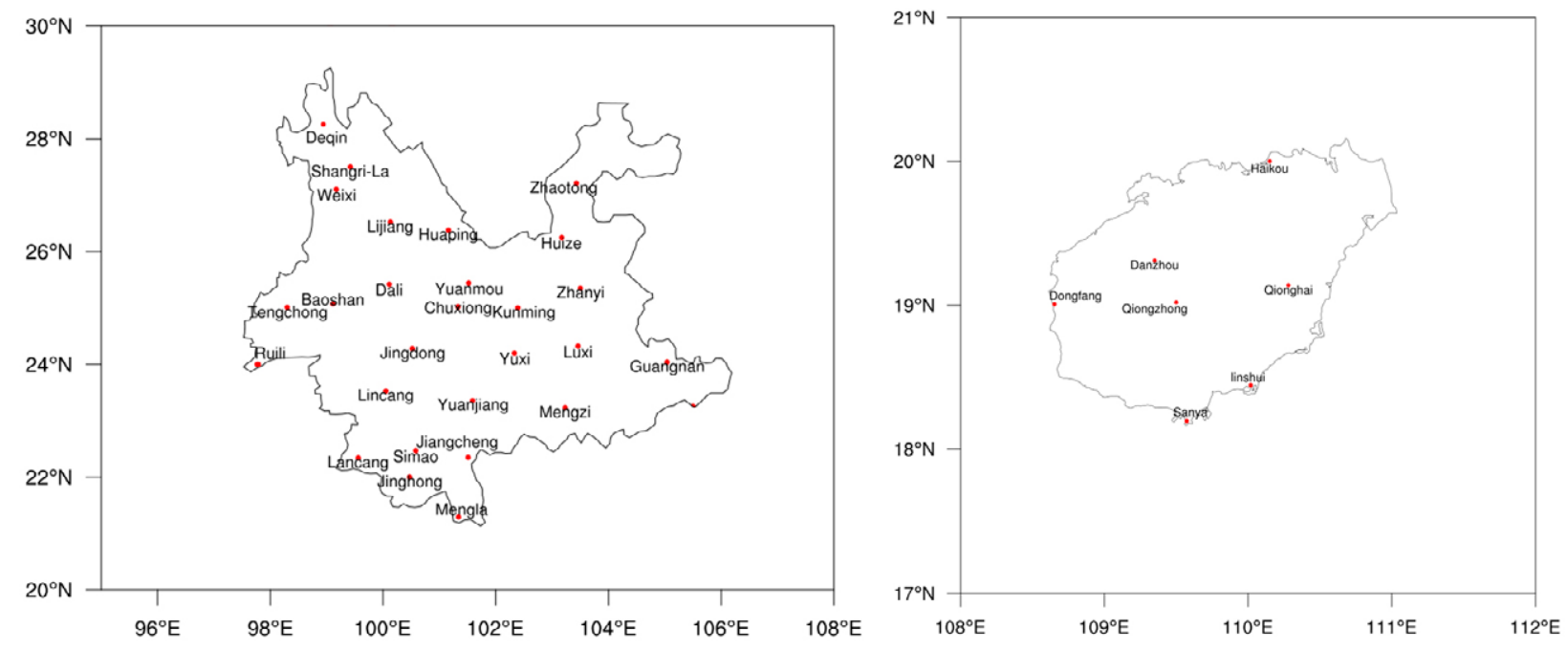

Figure 1. Locations of the 27 Yunnan (left) and 7 Hainan (right) stations 


\section{Comprehensive Comfort Index (CCI)}

The CCI is a composite of three indices (THI, WEI, and ICL) used to represent tourism climate comfort (Xin et al., 2019) and is derived as follows:

$C C I=0.6 X_{T H I}+0.3 X_{W E I}+0.1 X_{I C L}$

Developed in 1959 by the US Meteorological Administration (Thom, 1959), the THI integrates temperature and humidity to quantify heat exchange between the human body and its surrounding environment:

$$
T H I=(1.8 t+32)-0.55(1-f)(1.8 t-26)
$$

where $t$ represents air temperature in degrees Celsius $\left({ }^{\circ} \mathrm{C}\right)$ and $\mathrm{f}$ is relative humidity (\%).

The WEI was introduced in 1966 as an improved version of the wind chill index (Terjung et al., 1966). Incorporating different combinations of wind speed and temperature, in conjunction with heat dissipation by the human body, the WEI quantifies the degree to which human skin experiences the effects of warm and cold wind according to the equation:

$$
W E I=-(10 \sqrt{V}+10.45-V)(33-t)+8.55 S
$$

where $t$ denotes air temperature $\left({ }^{\circ} \mathrm{C}\right), \mathrm{V}$ the surface wind speed $(\mathrm{m} / \mathrm{s})$, and $\mathrm{S}$ the hours of sunshine per day $(\mathrm{h} / \mathrm{d})$.

The fourth index, the ICL (de Freitas, 1979), accounts for the discomfort caused by climate change by considering the atmospheric and physiological variables that affect the thermal state of a human body outdoors:
$I C L=\frac{33-t}{0.155 H}-\frac{H+\alpha R \cos \alpha}{(0.62+19.0 \cdot \sqrt{V}) H}$

where $\mathrm{t}$ is air temperature $\left({ }^{\circ} \mathrm{C}\right), \mathrm{V}$ is surface wind speed $(\mathrm{m} / \mathrm{s}), \mathrm{a}=0.6, \mathrm{H}=87 \mathrm{~W} / \mathrm{m}^{2}$, and the solar constant $R=1367 \mathrm{~W} / \mathrm{m}^{2}$. In this equation, a represents the solar altitude angle, which in winter is generally set as $90-\beta-23^{\circ} 26^{\prime}$ ( $\beta$ denotes latitude; Xu et al., 2000). Ultimately, the individual THI, WEI, and ICL scores are implemented in equation (1) to calculate the CCI. The CCI classifications and grades are given in Table 1.

\section{Tourism Climate Index (TCI)}

The TCI (Mieczkowski, 1985) is a widely used tool that incorporates multiple meteorological factors:

$T C I=2(4 C I D=C I A=2 P=2 S=W)$

To refine the TCI, Shi (2016) made the addition of the THI, resulting in a more straightforward calculation:

$T C I=2(4 A T H I+M T H I+2 P+2 S+W)$

Here we calculate the TCI using equation (6), in which ATHI represents the maximal THI for a given day (derived from equation (2), with maximum air temperature and minimum relative humidity), and MTHI is the THI averaged over both day and night. The ATHI and MTHI classifications and scores are the same as those provided in figure 1 of Mieczkowski (1985). For equation (6), variables P, S, and W are average monthly precipitation, average monthly sunshine hours, and average monthly wind speed, respectively.

Table 1. CCl classification scheme

\begin{tabular}{|l|c|c|c|c|}
\hline $\begin{array}{l}\text { Comprehensive } \\
\text { Comfort Index }(\mathrm{CCl})\end{array}$ & $7 \leq \mathrm{CCl} \leq 9$ & $5 \leq \mathrm{CCl}<7$ & $3 \leq \mathrm{CCl}<5$ & $1 \leq \mathrm{CCl}<3$ \\
\hline Grade & Comfortable & Relatively comfortable & Less comfortable & Uncomfortable \\
\hline
\end{tabular}

Table 2. Classification scheme for the TCI

\begin{tabular}{|c|c|}
\hline Tourism Climate Index (TCI) & Description of tourist comfort level \\
\hline $90-100$ & Ideal \\
\hline $80-89$ & Excellent \\
\hline $70-79$ & Very Good \\
\hline $60-69$ & Cood \\
\hline $50-59$ & Acceptable \\
\hline $40-49$ & Marginal \\
\hline $30-39$ & Unfavorable \\
\hline $20-29$ & Very Unfavorable \\
\hline $10-29$ & Extremely Unfavorable \\
\hline$<9$ & Impossible \\
\hline
\end{tabular}


Classifications and scores for $\mathrm{P}, \mathrm{S}$, and $\mathrm{W}$ are provided in tables $1-3$ of Mieczkowski (1985). The TCI classifications are given here in Table 2.

\section{Cold surges}

East Asian cold surges are one of the most prominent wintertime meteorological phenomena in the Northern Hemisphere (Chang \& Lau, 1980) and involve the anomalous penetration of cold, high-latitude air masses into lower latitudes. Environmentally, cold surges can result in severe weather impacts such as gales, cold temperatures, frost, freezing rain, and sandstorms over large areas of East and Southeast Asia (Ding, 1990). Physiologically, these events decrease the effective temperature (ET) experienced by the human body, which in turn impacts climate comfort (Wu et al., 2017ab). The mean low-level, meridional, northerly wind component is employed as an index for cold surge intensity (Chang and Lau, 1980). Specifically, a cold surge occurs when northerly airflow at $925 \mathrm{hPa}$ over the northern South China Sea $\left(15^{\circ}-20^{\circ} \mathrm{N}, 110^{\circ}-115^{\circ} \mathrm{E}\right.$ ) increases to $8 \mathrm{~m} / \mathrm{s}$ (Lau et al., 1983; Ding, 1990). To identify individual wintertime cold surges between 1981 and 2010, we employed NCEP/NCAR Reanalysis 1 data provided by the National Centers for Environmental Prediction/ National Weather Service and the National Oceanic and Atmospheric Administration (NOAA) of the United States (NCEP/NCAR Reanalysis 1: NOAA Physical Sciences Laboratory). These data are provided four times daily and have a spatial resolution of $2.5^{\circ} \times 2.5^{\circ}$.

\section{Results}

\section{Comparison between the $\mathrm{CCl}$ and $\mathrm{TCl}$}

Distributions of mean wintertime CCI and TCI for Yunnan and Hainan provinces between 1981 and 2010 are shown in Figures 2 and 3; detailed classifications of both indices are given in Tables 3-5. In Hainan, both indices exhibit relatively high scores (Figs 2 and 3 ), indicating that the island province is climatically comfortable for hibernation tourism during winter. A key difference between the CCI and TCI occurs in Sanya, for which the former assigns a Relatively Comfortable $(\mathrm{CCI}=6)$ grade in February, while the latter gives an Ideal (TCI = 90) score (Table 5). Although the TCI temperature standard is relatively high (i.e., an ET of $20^{\circ} \mathrm{C}-27^{\circ} \mathrm{C}$ is considered optimal), that same range is considered to be hot and only relatively comfortable in the CCI. According to Lin et al. (2003) and Huang (2016), Sanya is classified as hot in winter, which is more consistent with the CCI classification.

Larger discrepancies between the two indices occur in Yunnan (Figs 2 and 3). In Figure 2, for instance, the CCI identifies uncomfortable areas primarily in northwestern Yunnan, whereas the TCI provides relatively low scores for northeastern and eastern Yunnan. Other disparities include Shangri-La, which is assigned an Uncomfortable wintertime score by the CCI $(<3)$ owing to the prevalence of cold and windy conditions, but which is described as Good by the TCI (60-69) on account of the long sunshine hours (Tables 3-5). Consequently, the CCI deems Shangri-La unsuitable for tourism, whereas the TCI, which is more strongly weighted towards sunshine hours, considers the region suitable. Similarly, while the CCI gives Huaping a Relatively Comfortable grade $(\mathrm{CCI}=5.6)$ for the month of January, the TCI describes this location as Excellent $(\mathrm{TCI}=81$; Table 4 ), owing largely to its long sunshine hours $(8 \mathrm{~h} / \mathrm{d})$. The biggest (smallest) differences in Yunnan are in January (February), for which 12 (5) stations give conflicting CCI and TCI classifications (Tables 3 and 5). We note that both indices agree that the most comfortable locations for hibernation tourists are in southwestern Yunnan.

Generally speaking, the CCI and TCI give more consistent results for Hainan, suggesting that the province is more climatically suitable than Yunnan for hibernation tourism. Because the TCI demonstrates a preference of long sunshine hours, the typically dry and sunny climate of Yunnan in winter affords the province an Acceptable score on this index (TCI > 50; Tables 3-5). The CCI, in contrast, classes certain parts of Yunnan (e.g., Deqin, Shangri-La, and Zhaotong) as Uncomfortable (Tables 3-5 and Fig. 2). There is also disagreement on which sites are optimal for hibernation tourism; Jiangcheng and Mengzi in Yunnan are considered Comfortable by the CCI, but do not score as highly in the TCI.

Temporal changes in the CCI and TCI for Hainan are depicted in Figure 4, where they are compared directly with tourist reception numbers (http://lwt. hainan.gov.cn/xxgk 55333/lytj/2019data/). Overall tourist reception numbers for the province have been available since 1998, and monthly reception numbers (including winter months) have been available since 2002. Our comparison of CCI and TCI scores is restricted to the period 2002-2010. The obvious upward trend in tourist reception numbers for Hainan (Fig. 4: blue line) reflects the development of Chinese tourism over that period. To account for this factor, we have detrended the data (i.e., the linear trend is fitted and subtracted from the original data; blue bars in Fig. 4). Table 6 lists the correlations between the CCI 

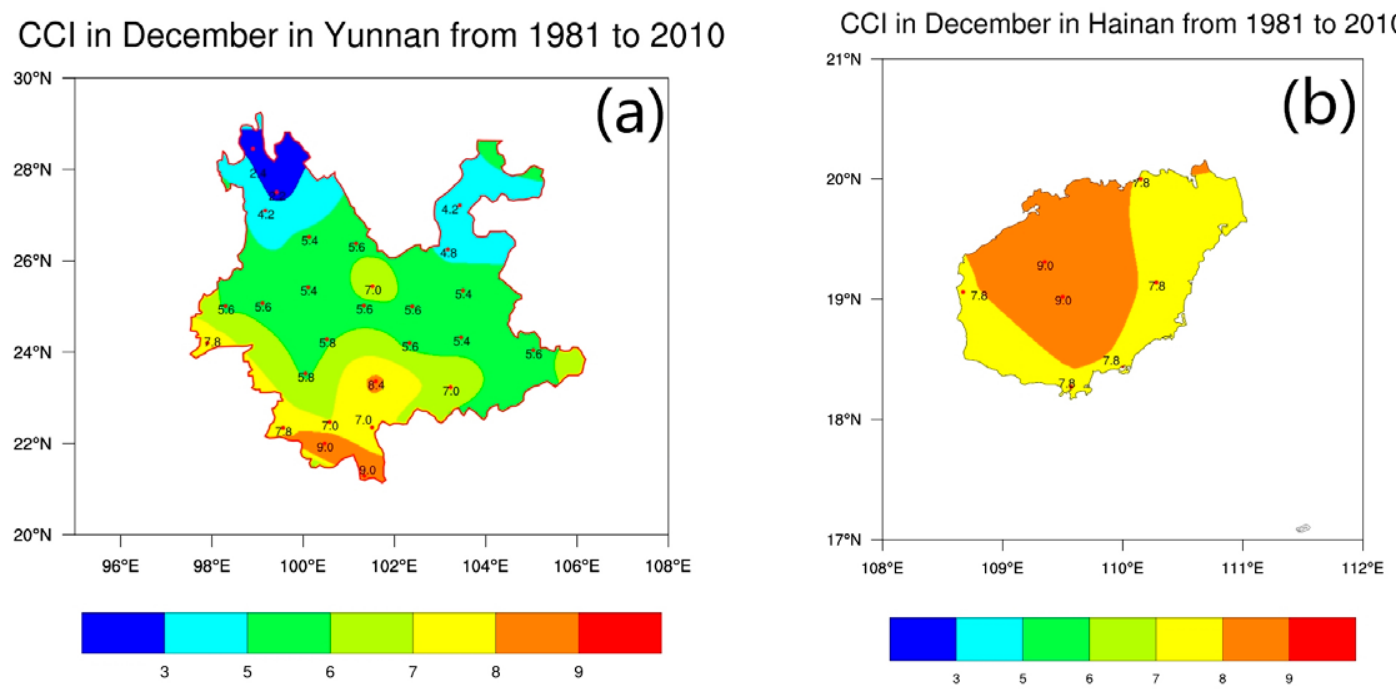

CCl in January in Yunnan from 1981 to 2010

CCl in January in Hainan from 1981 to 2010
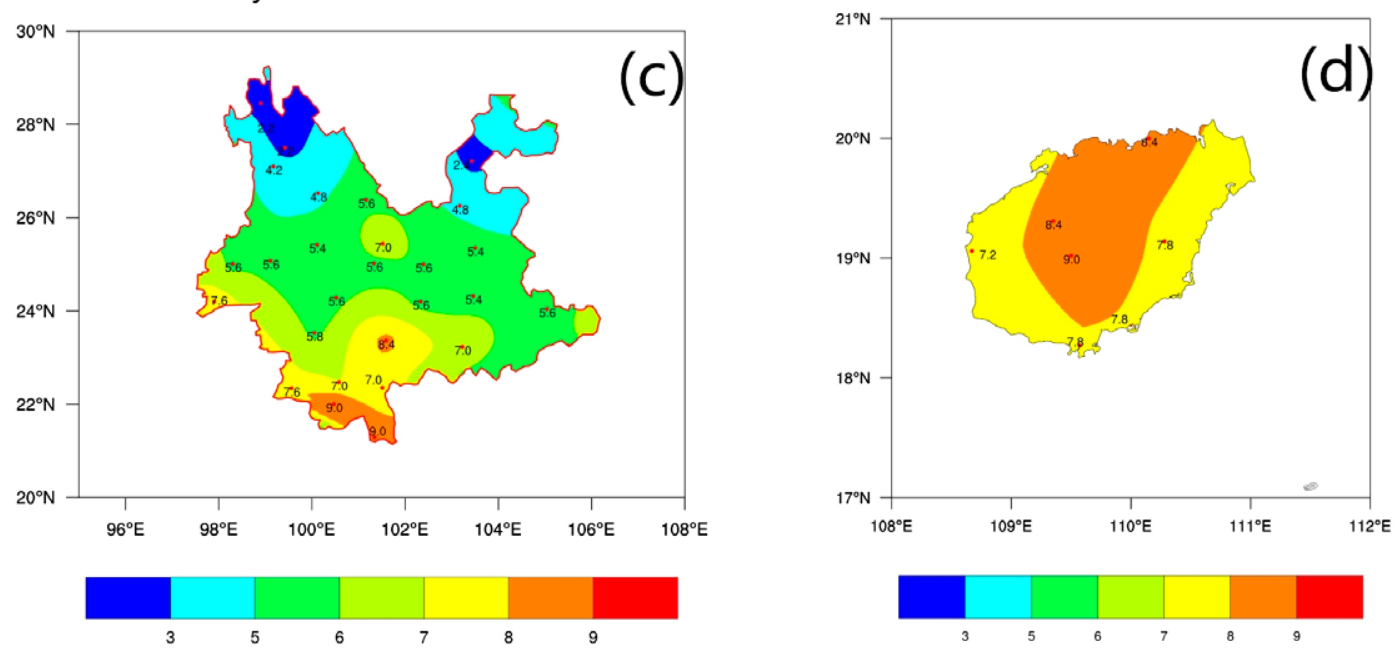

$\mathrm{CCl}$ in February in Yunnan from 1981 to 2010

CCl in February in Hainan from 1981 to 2010
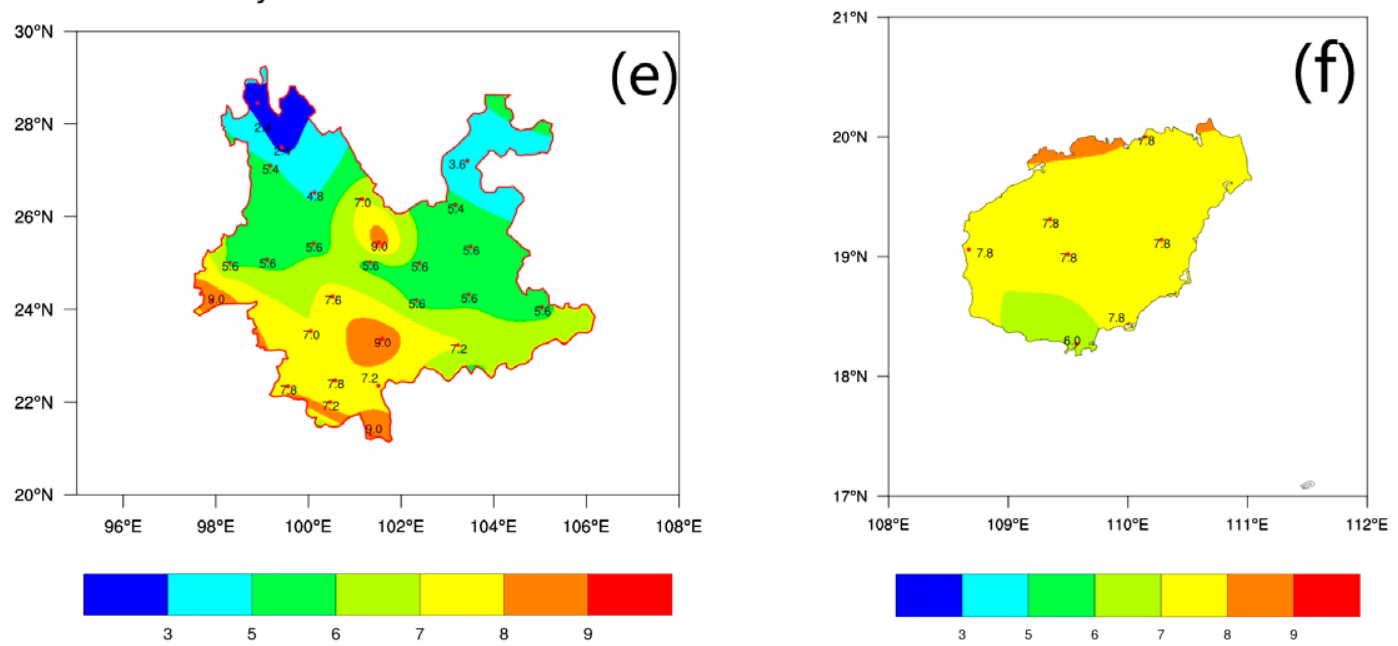

Figure 2. Mean CCI distributions for ( $a$ and b) December, (c and d) January, and (e and f) February for the period 19812010. Panels (a), (c), and (e) correspond to Yunnan Province, and Hainan Province is depicted in panels (b), (d), and (f). On this color scale, $7 \leq \mathrm{CCl} \leq 9$ is Comfortable, $5 \leq \mathrm{CCl}<7$ is Relatively Comfortable, $3 \leq \mathrm{CCl}<5$ is Less Comfortable, and $1 \leq$ $\mathrm{CCl}<3$ is Uncomfortable 
$\mathrm{TCl}$ in December in Yunnan from 1981 to 2010

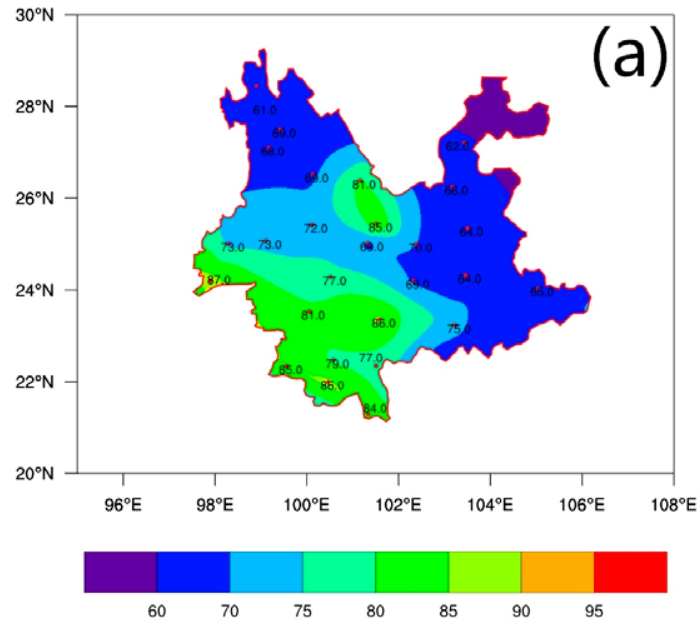

TCl in January in Yunnan from 1981 to 2010

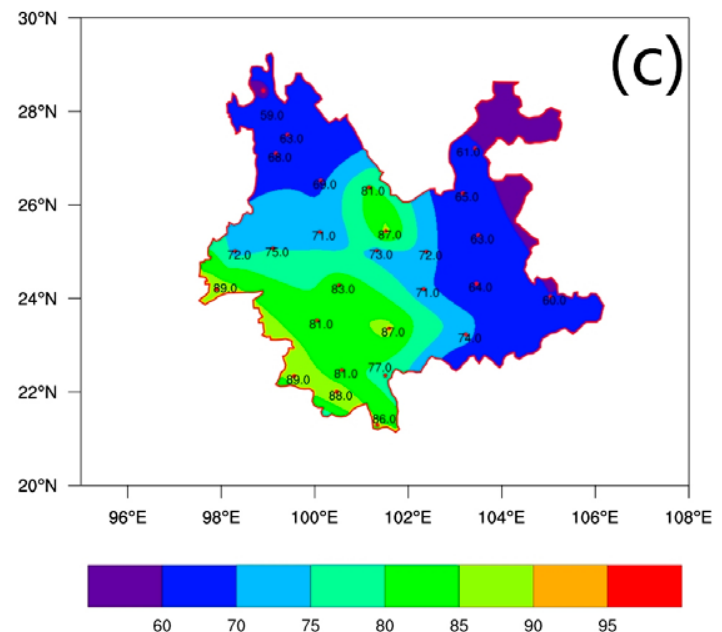

$\mathrm{TCl}$ in February in Yunnan from 1981 to 2010

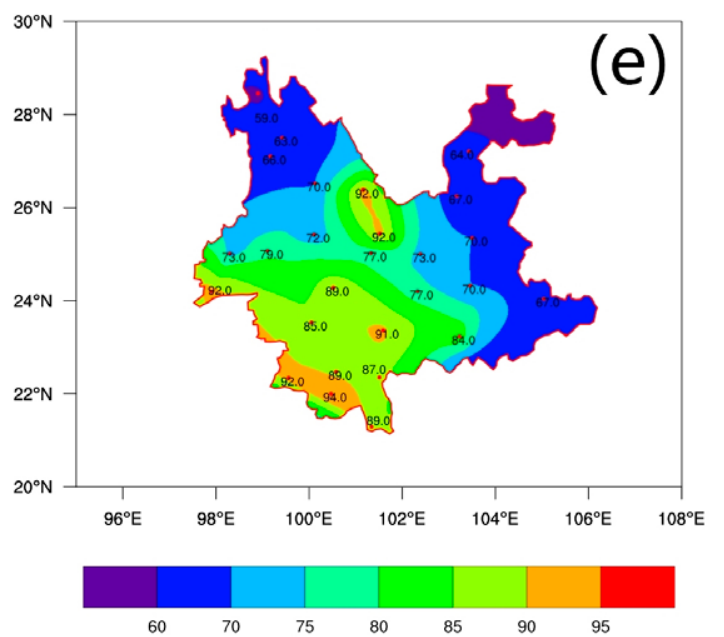

$\mathrm{TCl}$ in December in Hainan from 1981 to 2010

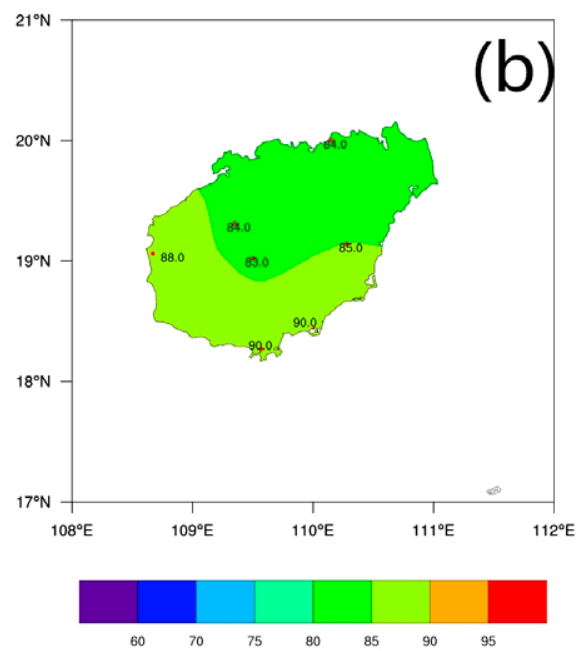

TCl in January in Hainan from 1981 to 2010

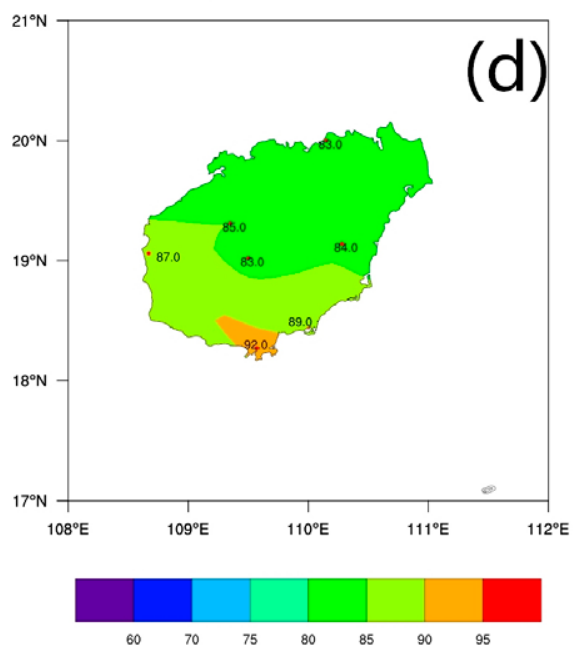

$\mathrm{TCl}$ in February in Hainan from 1981 to 2010

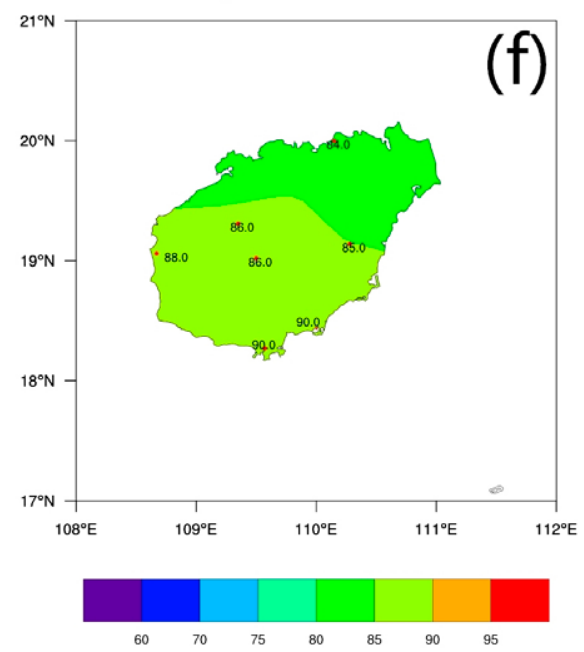

Figure 3. Mean TCl distributions for ( $a$ and b) December, ( $c$ and d) January, and (e and f) February for the period 19812010. Panels (a), (c), and (e) correspond to Yunnan Province, and Hainan Province is depicted in panels (b), (d), and (f). On this color scale, $90-100$ is Ideal, 80-89 is Excellent, 70-79 is Very Good, 60-69 is Good, and 50-59 is Acceptable 
Can Tourism Climatic Indices Reflect

the Impact of Cold Surges?

Table 3. December $\mathrm{CCl}$ and $\mathrm{TCl}$ classifications for Yunnan (first 27 stations) and Hainan (last 7 stations) provinces between 1981 and 2010.

\begin{tabular}{|c|c|c|c|c|c|c|c|c|}
\hline \multirow{2}{*}{$\begin{array}{l}\text { Index } \\
\text { Station Grade }\end{array}$} & \multicolumn{4}{|c|}{$\mathrm{CCl}$} & \multicolumn{4}{|c|}{$\mathrm{TCl}$} \\
\hline & $7 \leq \mathrm{CCl} \leq 9$ & $5 \leq \mathrm{CCl}<7$ & $3 \leq \mathrm{CCl}<5$ & $1 \leq \mathrm{CCl}<3$ & $80-100$ & $70-79$ & $60-69$ & $50-59$ \\
\hline Deqin & & & & $\sqrt{ }$ & & & $\sqrt{ }$ & \\
\hline Shangri-La & & & & $\sqrt{ }$ & & & $\sqrt{ }$ & \\
\hline Weixi & & & $\sqrt{ }$ & & & & $\sqrt{ }$ & \\
\hline Zhaotong & & & $\sqrt{ }$ & & & & $\sqrt{ }$ & \\
\hline Lijiang & & $\sqrt{ }$ & & & & & $\sqrt{ }$ & \\
\hline Huaping & & $\sqrt{ }$ & & & $\sqrt{ }$ & & & \\
\hline Huize & & & $\sqrt{ }$ & & & & $\sqrt{ }$ & \\
\hline Tengchong & & $\sqrt{ }$ & & & & $\sqrt{ }$ & & \\
\hline Baoshan & & $\sqrt{ }$ & & & & $\sqrt{ }$ & & \\
\hline Dali & & $\sqrt{ }$ & & & & $\sqrt{ }$ & & \\
\hline Yuanmou & $\sqrt{ }$ & & & & $\sqrt{ }$ & & & \\
\hline Chuxiong & & $\sqrt{ }$ & & & & & $\sqrt{ }$ & \\
\hline Kunming & & $\sqrt{ }$ & & & & $\sqrt{ }$ & & \\
\hline Zhanyi & & $\sqrt{ }$ & & & & & $\sqrt{ }$ & \\
\hline Ruili & $\sqrt{ }$ & & & & $\sqrt{ }$ & & & \\
\hline Jingdong & & $\sqrt{ }$ & & & & $\sqrt{ }$ & & \\
\hline Yuxi & & $\sqrt{ }$ & & & & & $\sqrt{ }$ & \\
\hline Luxi & & $\sqrt{ }$ & & & & & $\sqrt{ }$ & \\
\hline Lincang & & $\sqrt{ }$ & & & $\sqrt{ }$ & & & \\
\hline Lancang & $\sqrt{ }$ & & & & $\sqrt{ }$ & & & \\
\hline Jinghong & $\sqrt{ }$ & & & & $\sqrt{ }$ & & & \\
\hline Simao & $\sqrt{ }$ & & & & & $\sqrt{ }$ & & \\
\hline Yuanjiang & $\sqrt{ }$ & & & & $\sqrt{ }$ & & & \\
\hline Mengla & $\sqrt{ }$ & & & & $\sqrt{ }$ & & & \\
\hline Jiangcheng & $\sqrt{ }$ & & & & & $\sqrt{ }$ & & \\
\hline Mengzi & $\sqrt{ }$ & & & & & $\sqrt{ }$ & & \\
\hline Guangnan & & $\sqrt{ }$ & & & & & $\sqrt{ }$ & \\
\hline Haikou & $\sqrt{ }$ & & & & $\sqrt{ }$ & & & \\
\hline Dongfang & $\sqrt{ }$ & & & & $\sqrt{ }$ & & & \\
\hline Danzhou & $\sqrt{ }$ & & & & $\sqrt{ }$ & & & \\
\hline Qiongzhong & $\sqrt{ }$ & & & & $\sqrt{ }$ & & & \\
\hline Qionghai & $\sqrt{ }$ & & & & $\sqrt{ }$ & & & \\
\hline Sanya & $\sqrt{ }$ & & & & $\sqrt{ }$ & & & \\
\hline Lingshui & $\sqrt{ }$ & & & & $\sqrt{ }$ & & & \\
\hline
\end{tabular}


Table 4. January $\mathrm{CCl}$ and $\mathrm{TCl}$ classifications for Yunnan (first 27 stations) and Hainan (last 7 stations) provinces between 1981 and 2010.

\begin{tabular}{|c|c|c|c|c|c|c|c|c|}
\hline \multirow{2}{*}{$\begin{array}{l}\text { Index } \\
\text { Station Grade }\end{array}$} & \multicolumn{4}{|c|}{$\mathrm{CCl}$} & \multicolumn{4}{|c|}{$\mathrm{TCl}$} \\
\hline & $7 \leq \mathrm{CCl} \leq 9$ & $5 \leq \mathrm{CCl}<7$ & $3 \leq \mathrm{CCl}<5$ & $1 \leq \mathrm{CCl}<3$ & $80-100$ & $70-79$ & $60-69$ & $50-59$ \\
\hline Deqin & & & & $\sqrt{ }$ & & & & $\sqrt{ }$ \\
\hline Shangri-La & & & & $\sqrt{ }$ & & & $\sqrt{ }$ & \\
\hline Weixi & & & $\sqrt{ }$ & & & & $\sqrt{ }$ & \\
\hline Zhaotong & & & & $\sqrt{ }$ & & & $\sqrt{ }$ & \\
\hline Lijiang & & $\sqrt{ }$ & & & & & $\sqrt{ }$ & \\
\hline Huaping & & $\sqrt{ }$ & & & $\sqrt{ }$ & & & \\
\hline Huize & & & $\sqrt{ }$ & & & & $\sqrt{ }$ & \\
\hline Tengchong & & $\sqrt{ }$ & & & & $\sqrt{ }$ & & \\
\hline Baoshan & & $\sqrt{ }$ & & & & $\sqrt{ }$ & & \\
\hline Dali & & $\sqrt{ }$ & & & & $\sqrt{ }$ & & \\
\hline Yuanmou & $\sqrt{ }$ & & & & $\sqrt{ }$ & & & \\
\hline Chuxiong & & $\sqrt{ }$ & & & & $\sqrt{ }$ & & \\
\hline Kunming & & $\sqrt{ }$ & & & & $\sqrt{ }$ & & \\
\hline Zhanyi & & $\sqrt{ }$ & & & & & $\sqrt{ }$ & \\
\hline Ruili & $\sqrt{ }$ & & & & $\sqrt{ }$ & & & \\
\hline Jingdong & & $\sqrt{ }$ & & & $\sqrt{ }$ & & & \\
\hline Yuxi & & $\sqrt{ }$ & & & & $\sqrt{ }$ & & \\
\hline Luxi & & $\sqrt{ }$ & & & & & $\sqrt{ }$ & \\
\hline Lincang & & $\sqrt{ }$ & & & $\sqrt{ }$ & & & \\
\hline Lancang & $\sqrt{ }$ & & & & $\sqrt{ }$ & & & \\
\hline Jinghong & $\sqrt{ }$ & & & & $\sqrt{ }$ & & & \\
\hline Simao & $\sqrt{ }$ & & & & $\sqrt{ }$ & & & \\
\hline Yuanjiang & $\sqrt{ }$ & & & & $\sqrt{ }$ & & & \\
\hline Mengla & $\sqrt{ }$ & & & & $\sqrt{ }$ & & & \\
\hline Jiangcheng & $\sqrt{ }$ & & & & & $\sqrt{ }$ & & \\
\hline Mengzi & $\sqrt{ }$ & & & & & $\sqrt{ }$ & & \\
\hline Guangnan & & $\sqrt{ }$ & & & & & $\sqrt{ }$ & \\
\hline Haikou & $\sqrt{ }$ & & & & $\sqrt{ }$ & & & \\
\hline Dongfang & $\sqrt{ }$ & & & & $\sqrt{ }$ & & & \\
\hline Danzhou & $\sqrt{ }$ & & & & $\sqrt{ }$ & & & \\
\hline Qiongzhong & $\sqrt{ }$ & & & & $\sqrt{ }$ & & & \\
\hline Qionghai & $\sqrt{ }$ & & & & $\sqrt{ }$ & & & \\
\hline Sanya & $\sqrt{ }$ & & & & $\sqrt{ }$ & & & \\
\hline Lingshui & $\sqrt{ }$ & & & & $\sqrt{ }$ & & & \\
\hline
\end{tabular}


Can Tourism Climatic Indices Reflect

the Impact of Cold Surges?

Table 5. February $\mathrm{CCl}$ and $\mathrm{TCl}$ classifications for Yunnan (first 27 stations) and Hainan (last 7 stations) provinces between 1981 and 2010.

\begin{tabular}{|c|c|c|c|c|c|c|c|c|}
\hline \multirow{2}{*}{$\begin{array}{l}\text { Index } \\
\text { Station Grade }\end{array}$} & \multicolumn{4}{|c|}{$\mathrm{CCl}$} & \multicolumn{4}{|c|}{$\mathrm{TCl}$} \\
\hline & $7 \leq \mathrm{CCl} \leq 9$ & $5 \leq \mathrm{CCl}<7$ & $3 \leq \mathrm{CCl}<5$ & $1 \leq \mathrm{CCl}<3$ & $80-100$ & $70-79$ & $60-69$ & $50-59$ \\
\hline Deqin & & & & $\sqrt{ }$ & & & & $\sqrt{ }$ \\
\hline Shangri-La & & & & $\sqrt{ }$ & & & $\sqrt{ }$ & \\
\hline Weixi & & & $\sqrt{ }$ & & & & $\sqrt{ }$ & \\
\hline Zhaotong & & & & $\sqrt{ }$ & & & $\sqrt{ }$ & \\
\hline Lijiang & & & $\sqrt{ }$ & & & $\sqrt{ }$ & & \\
\hline Huaping & $\sqrt{ }$ & & & & $\sqrt{ }$ & & & \\
\hline Huize & & $\sqrt{ }$ & & & & & $\sqrt{ }$ & \\
\hline Tengchong & & $\sqrt{ }$ & & & & $\sqrt{ }$ & & \\
\hline Baoshan & & $\sqrt{ }$ & & & & $\sqrt{ }$ & & \\
\hline Dali & & $\sqrt{ }$ & & & & $\sqrt{ }$ & & \\
\hline Yuanmou & $\sqrt{ }$ & & & & $\sqrt{ }$ & & & \\
\hline Chuxiong & & $\sqrt{ }$ & & & & $\sqrt{ }$ & & \\
\hline Kunming & & $\sqrt{ }$ & & & & $\sqrt{ }$ & & \\
\hline Zhanyi & & $\sqrt{ }$ & & & & $\sqrt{ }$ & & \\
\hline Ruili & $\sqrt{ }$ & & & & $\sqrt{ }$ & & & \\
\hline Jingdong & $\sqrt{ }$ & & & & $\sqrt{ }$ & & & \\
\hline Yuxi & & $\sqrt{ }$ & & & & $\sqrt{ }$ & & \\
\hline Luxi & & $\sqrt{ }$ & & & & $\sqrt{ }$ & & \\
\hline Lincang & $\sqrt{ }$ & & & & $\sqrt{ }$ & & & \\
\hline Lancang & $\sqrt{ }$ & & & & $\sqrt{ }$ & & & \\
\hline Jinghong & $\sqrt{ }$ & & & & $\sqrt{ }$ & & & \\
\hline Simao & $\sqrt{ }$ & & & & $\sqrt{ }$ & & & \\
\hline Yuanjiang & $\sqrt{ }$ & & & & $\sqrt{ }$ & & & \\
\hline Mengla & $\sqrt{ }$ & & & & $\sqrt{ }$ & & & \\
\hline Jiangcheng & $\sqrt{ }$ & & & & $\sqrt{ }$ & & & \\
\hline Mengzi & $\sqrt{ }$ & & & & $\sqrt{ }$ & & & \\
\hline Guangnan & & $\sqrt{ }$ & & & & & $\sqrt{ }$ & \\
\hline Haikou & $\sqrt{ }$ & & & & $\sqrt{ }$ & & & \\
\hline Dongfang & $\sqrt{ }$ & & & & $\sqrt{ }$ & & & \\
\hline Danzhou & $\sqrt{ }$ & & & & $\sqrt{ }$ & & & \\
\hline Qiongzhong & $\sqrt{ }$ & & & & $\sqrt{ }$ & & & \\
\hline Qionghai & $\sqrt{ }$ & & & & $\sqrt{ }$ & & & \\
\hline Sanya & & $\sqrt{ }$ & & & $\sqrt{ }$ & & & \\
\hline Lingshui & $\sqrt{ }$ & & & & $\sqrt{ }$ & & & \\
\hline
\end{tabular}




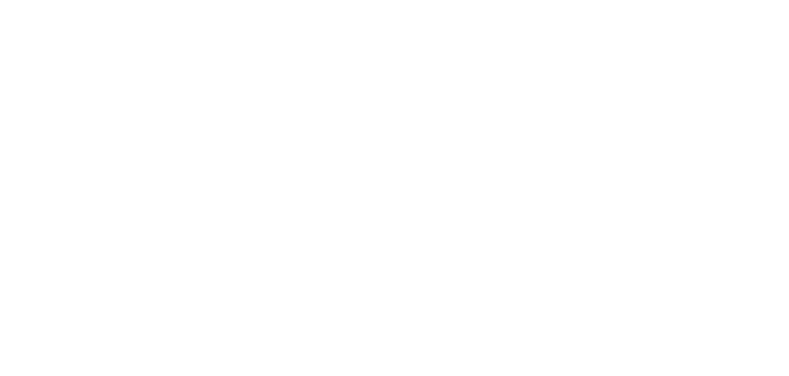

Figure 4. Temporal changes in $\mathrm{CCl}$ (left vertical axis; red line) and $\mathrm{TCl}$ (right vertical axis; green line) scores, hotel reception numbers (right vertical axis; black line; unit: 10,000 people), the linear trend of hotel reception numbers (blue line), and anomalies in hotel reception numbers after detrending (left vertical axis; blue bars) for winter (December, January and February) on Hainan between 2002 and 2010 [click on figure to enlarge]

(TCI) and hotel reception numbers and detrended hotel reception numbers for Hainan. We observe that, although the TCI and CCI both exhibit positive correlations ( 0.153 and 0.096 , respectively) with the detrended tourist reception data, these correlations are not significant, implying that tourism is influenced by factors other than climate, such as infrastructure, propagation of social media in tourist centers, regional economic development, and epidemic outbreaks.

Table 6. Correlation coefficients for the $\mathrm{CCl}$ and $\mathrm{TCl}$, hotel reception numbers, and anomalies of hotel reception numbers (after detrending) on Hainan.

\begin{tabular}{|c|c|c|}
\hline Correlations & $\begin{array}{c}\text { Hotel reception } \\
\text { numbers }\end{array}$ & $\begin{array}{c}\text { Anomalies in hotel } \\
\text { reception numbers } \\
\text { after detrending }\end{array}$ \\
\hline $\mathrm{CCl}$ & -0.095 & 0.096 \\
\hline $\mathrm{TCl}$ & -0.046 & 0.153 \\
\hline
\end{tabular}

The period of climatic comfort is a critical factor for hibernation tourism. Since the TCI utilizes monthly data, this approach cannot quantify comfort levels on a daily basis. Therefore, the CCI is more appropriate for investigating climatically comfortable periods in high resolution. In this study, we focused our evaluation on those cities and tourism hotspots with relatively high CCI scores, including eight in Yunnan Province (Yuanmou, Ruili, Lancang, Jinghong, Simao, Yuanjiang, Mengla, and Mengzi) and five in Hainan Province (Haikou, Danzhou, Qiongzhong, QiongHai, and Sanya). Figure 5 depicts the numbers of Optimal days $(\mathrm{CCI}=9)$ in winter: Mengla exhibits the highest value (82 days), followed by Jinghong (64 days); all eight cities in Yunnan attain Optimal status in February. In Hainan, Qiongzhong experiences the highest number of Optimal days (47 days), whereas Haikou and Sanya both report zero Optimal days. Optimal

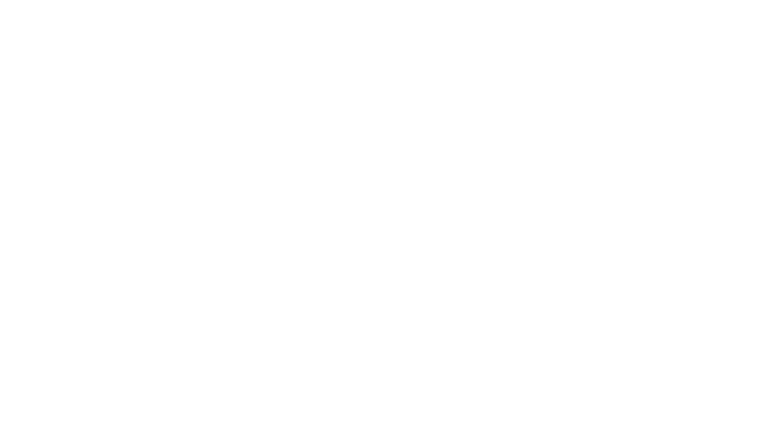

Figure 5. Number of days classed by the $\mathrm{CCl}$ as Optimal $(\mathrm{CCl}=9)$ during December (blue), January (red), and February (green) for eight cities in Yunnan (red rectangle: Yuanmou, Ruili, Lancang, Jinghong, Simao, Yuanjiang,

Mengla, and Mengzi) and five cities on Hainan (blue rectangle: Haikou, Danzhou, Qiongzhong, Qionghai, and Sanya)

[click on figure to enlarge]

days in Hainan are highest in January, underscoring a key difference in the timing of peak hibernation tourism between Yunnan and Hainan.

\section{Correlations with cold surges}

Figure 6 shows the comparison between TCI and CCI scores and the wintertime occurrence of cold surge days between 1981 and 2010 and highlights the strong interannual variability in cold surge events (blue line in Fig. 6). For Hainan and Yuanjiang (Yunnan), we observed a clear negative relationship between the occurrence of cold surge days and TCI scores, whereby a higher number of surge days corresponds to generally lower index scores. From this we infer that more frequent cold surge events result in a higher probability of low temperatures and high wind speeds. In contrast, the relationship between the occurrence of cold surge days and the CCI is less obvious.

Table 7 lists the correlation coefficients between the TCI and CCI and the number of cold surge days in Hainan and the cities of Yuanjiang, Mengla, and Jinghong in Yunnan between 1981 and 2010. The three Yunnan stations were selected because they are classified as being optimally comfortable during winter. Whereas correlation coefficients between the number of cold surge days and the TCI are all significantly negative, those for the CCI are more variable, being negative in Yuanjiang and Mengla but positive in Hainan and Jinghong. Moreover, the CCI correlation coefficients are not significant. This result indicates that the TCI reflects the influence of cold surges in a climatic perspective better than the CCI. As discussed in the previous section, the TCI has stricter temperature and sunshine hour thresholds, making the index generally more sensitive than the CCI to the influence of cold surges. 

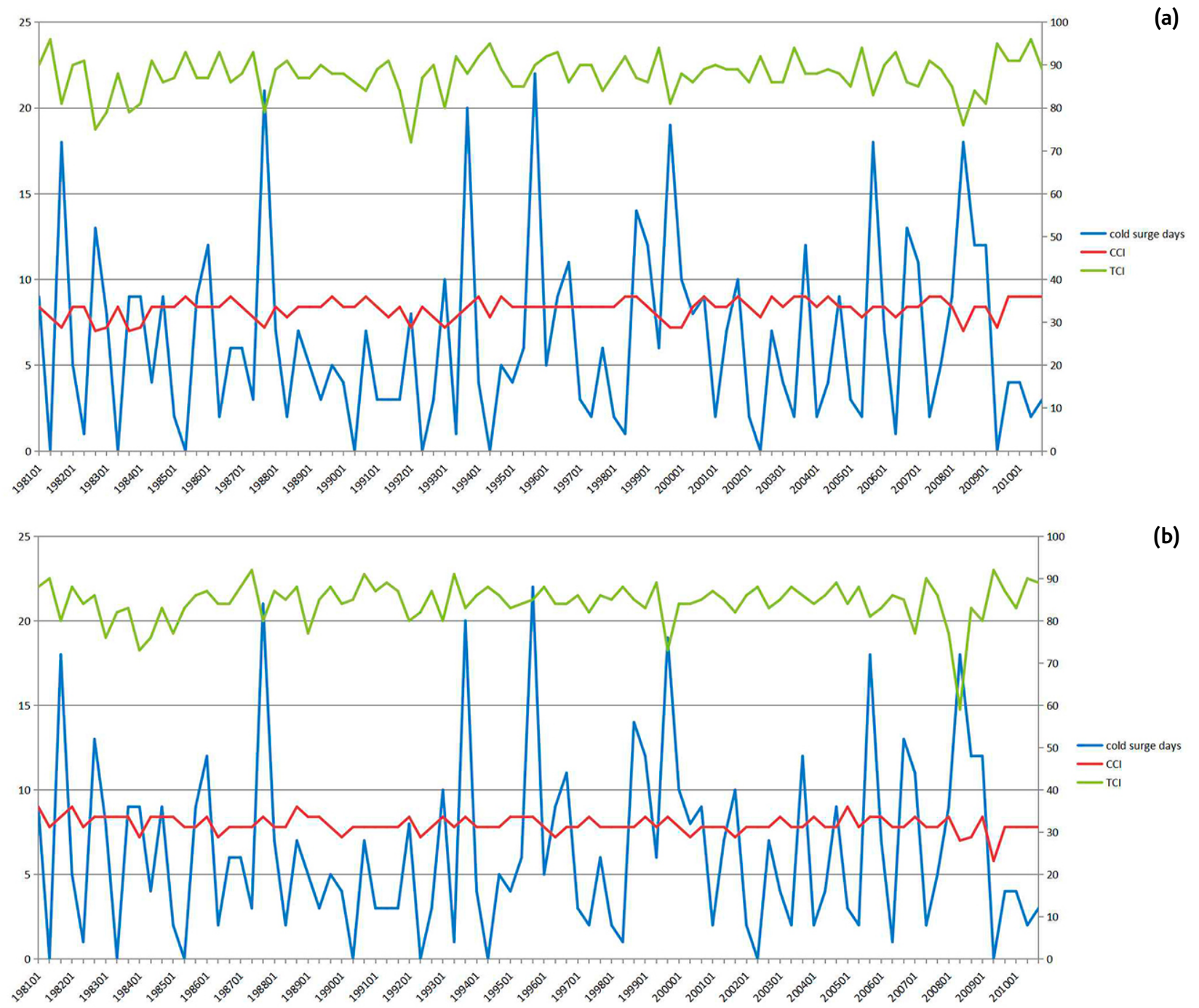

Figure 6. Monthly changes in the $\mathrm{CCl}$ (left vertical axis; red line) and $\mathrm{TCl}$ (right vertical axis; green line) relative to the incidence of cold surge days (left vertical axis; blue line) in winter for the period 1981-2010. Panel (a) corresponds to Yuanjiang in Yunnan; panel (b) depicts Hainan

Here we investigate the specific case of a strong East Asian cold surge, which occurred between 30 December 2004 and 2 January 2005 (Zhao \& Zeng, 2005). During this event, the South China Sea region and lower adjacent latitudes experienced anomalously strong winds and a pronounced drop in temperature. In Damaoshan (Hong Kong Province), for example, the air temperature dropped to $-2^{\circ} \mathrm{C}$ early in the morning of 1 January 2005. This cold anomaly even crossed the equator, pen- etrating the Southern Hemisphere and bringing heavy rainfall to northern Australia (Zhao \& Zeng, 2005). Between 30 and 31 December 2004, Hainan experienced significant cooling (Fig. 7), with temperatures in the mountainous central region dropping below $10^{\circ} \mathrm{C}$. During the same event, temperatures in northwestern and northeastern Yunnan dropped below freezing from 30 December 2004 to 1 January 2005 (Fig. 8). Despite the onset of warmer weather on 2 January 2005,

Table 7. Correlation coefficients between the $\mathrm{TCl}$ and $\mathrm{CCl}$, the $\mathrm{TCl}$ and cold surge days, and the $\mathrm{CCl}$ and cold surge days in Hainan and Yunnan (Yuanjiang, Jinghong, and Mengla) from 1981 to 2010 (* and ** denote significance levels of 95\% and $99 \%$, respectively)

\begin{tabular}{|l|c|c|c|c|c|}
\hline & $\mathrm{TCl}$ of Hainan & $\mathrm{TCl}$ of Yuanjiang & $\mathrm{TCl}$ of Jinghong & $\mathrm{TCl}$ of Mengla & Cold surge days \\
\hline Cold surge days & $-0.45^{*}$ & $-0.57^{* *}$ & $-0.49^{* *}$ & $-0.55^{* *}$ & \\
\hline $\mathrm{CCl}$ of Hainan & -0.12 & & & & 0.23 \\
\hline $\mathrm{CCl}$ of Yuanjiang & & $0.43^{*}$ & & & -0.25 \\
\hline $\mathrm{CCl}$ of Jinghong & & & $-0.41^{*}$ & & 0.26 \\
\hline $\mathrm{CCl}$ of Mengla & & & & -0.11 & -0.12 \\
\hline
\end{tabular}



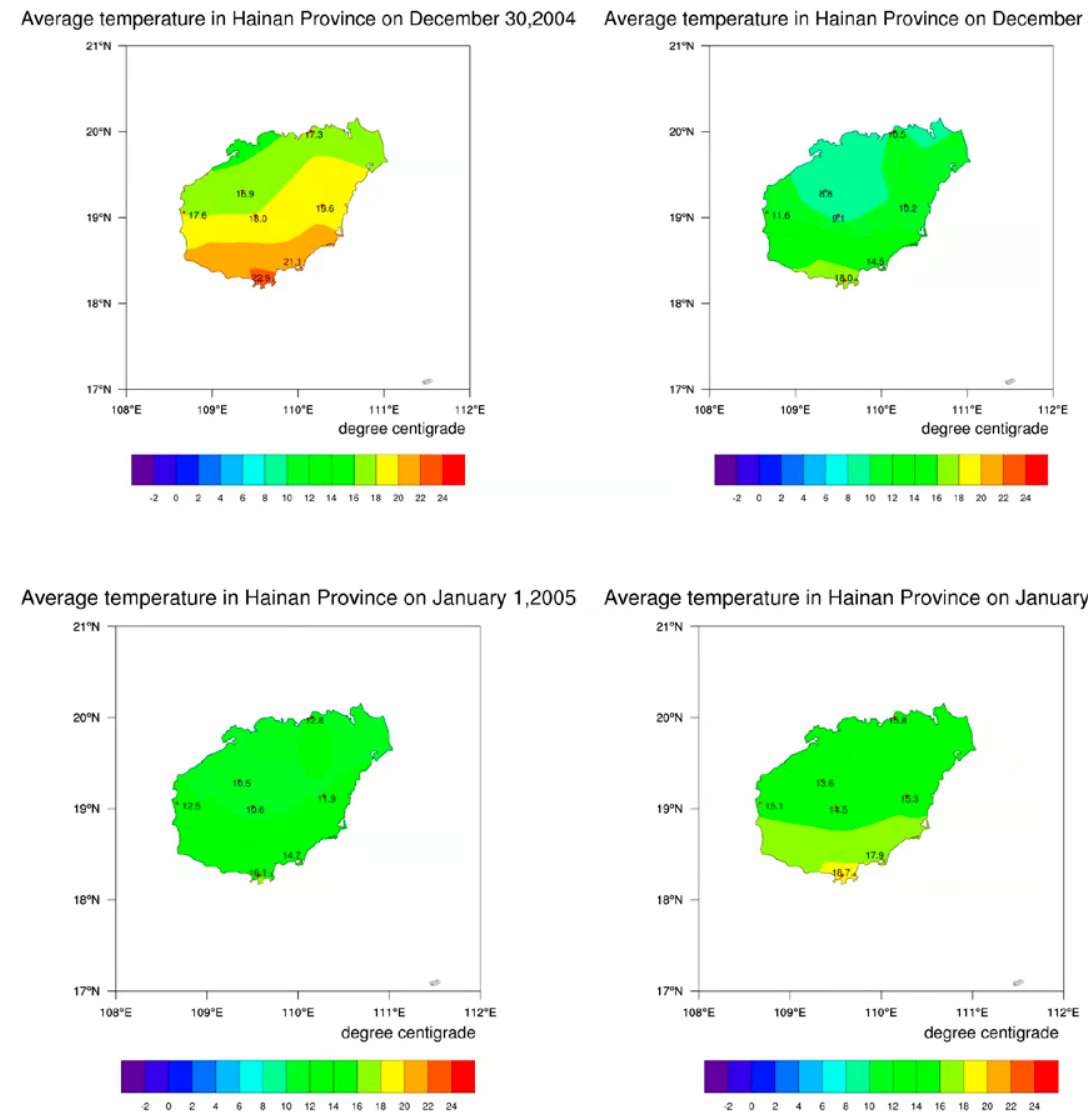

Figure 7. Daily temperature distributions for Hainan between 30 December 2004 and 2 January $2005\left({ }^{\circ} \mathrm{C}\right)$
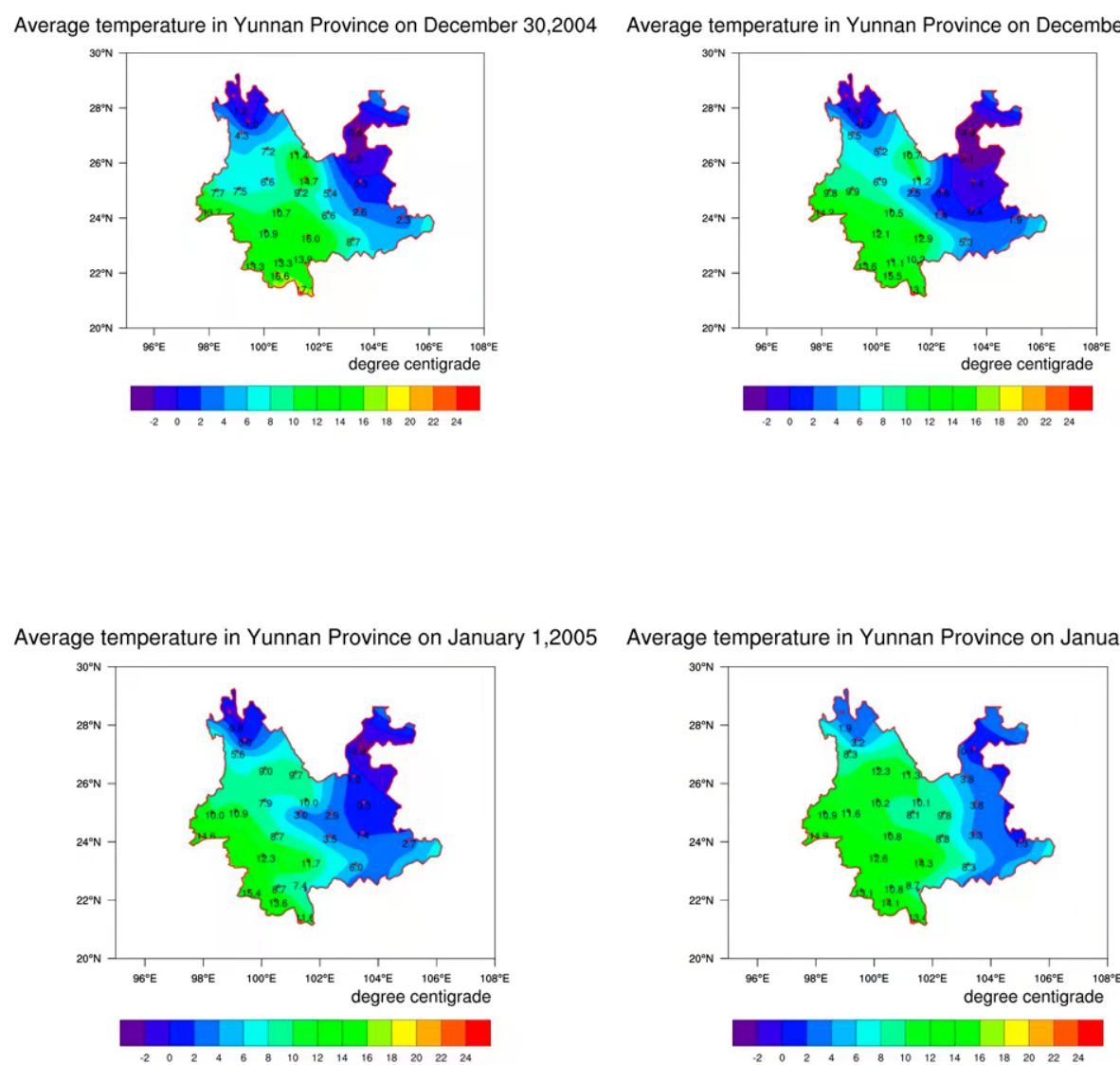

Figure 8. Daily temperature distributions for Yunnan between 30 December 2004 and 2 January $2005\left({ }^{\circ} \mathrm{C}\right)$ 

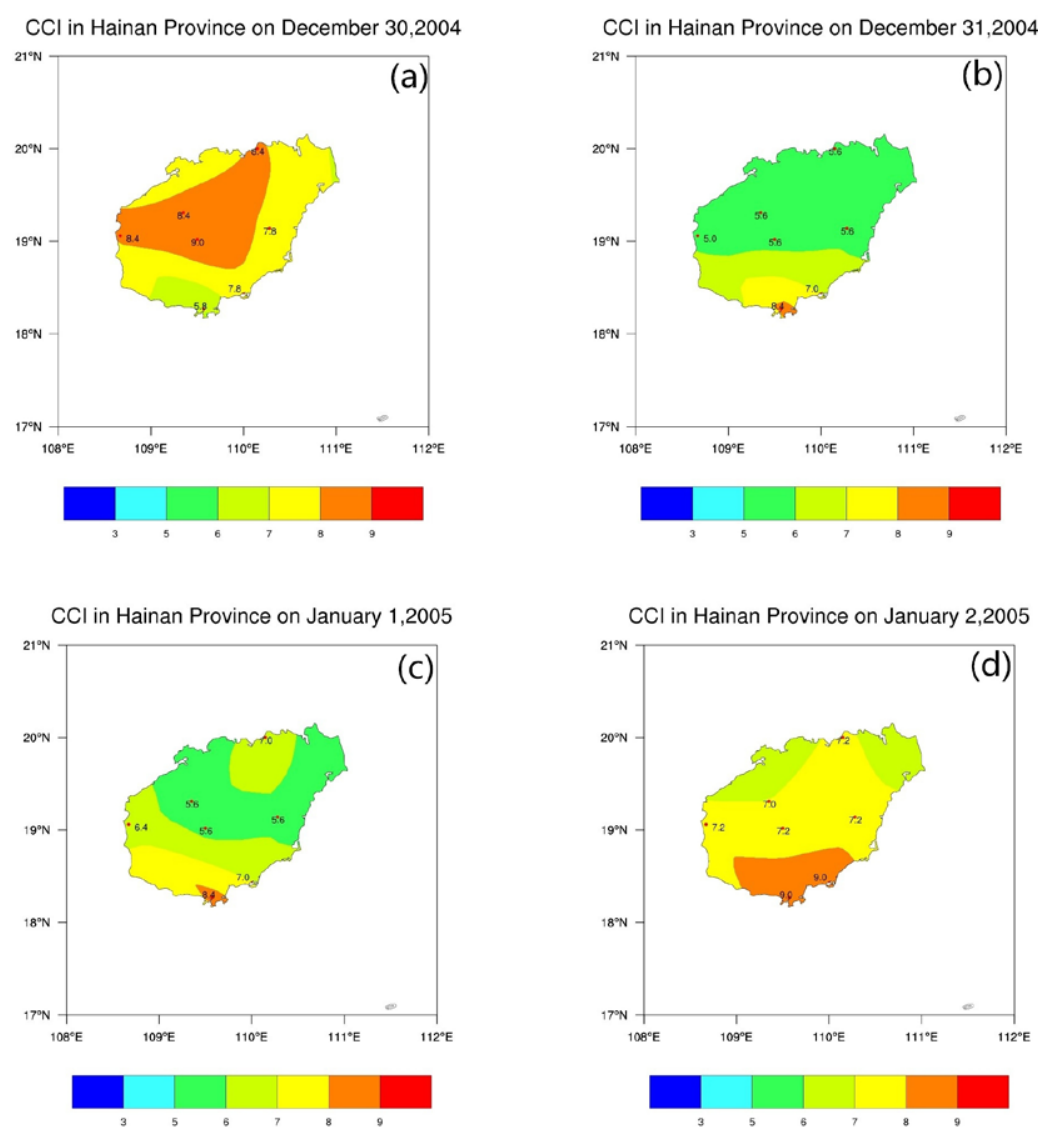

Figure 9. CCl distributions for Hainan between 30 December 2004 and 2 January 2005
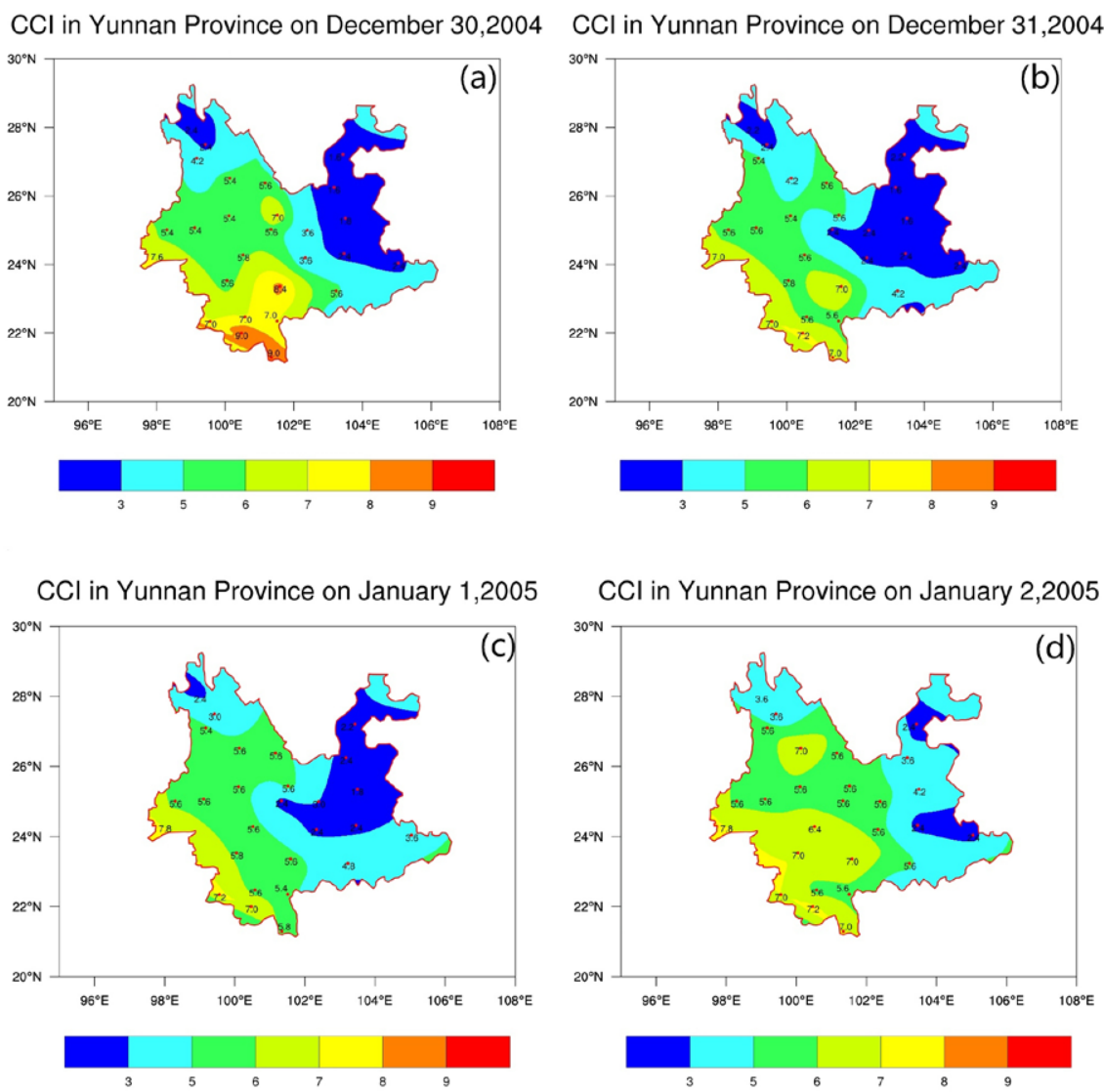

Figure 10. CCl distributions for Yunnan between 30 December 2004 and 2 January 2005 
temperatures in those regions remained anomalously low $\left(<4^{\circ} \mathrm{C}\right)$. In both Hainan and Yunnan, the cold surge was associated with elevated wind speeds and low precipitation ( $<3 \mathrm{~mm}$; not shown).

As a result of the 2004-2005 cold surge, CCI scores for both Hainan and Yunnan dropped measurably (Figs 9 and 10), with northwestern and northeastern
Yunnan registering Uncomfortable ratings (Fig. 10). The impact of this cold surge is captured effectively by the CCI; however, the monthly average resolution of the TCI precludes a direct comparison of the two indices. The inability of the TCI to quantify daily comfort conditions is thus a major limitation of this metric (Scott et al., 2016).

\section{Discussion and conclusions}

Winter tourism is an economically significant component of the tourism industry (Pullin et al., 2015). Although the potential impacts of climate change on this sector are the focus of research both globally (Scott et al., 2012) and regionally/nationally (Steiger \& Scott., 2020), previous work has focused primarily on the skiing industry (Steiger \& Stötter, 2013; Scott et al., 2019; 2020; Steiger et al., 2019; Steiger \& Scott., 2020), which is already being impacted by insufficient snow cover and shorter winter seasons (Steiger et al., 2019; Steiger \& Scott, 2020). In contrast, climatic impacts on hibernation tourism, particularly in China, are less well understood. Within the context of climate change, the declining number of extremely cold days in China (Wu et al., 2017a; Jin et al., 2019) suggests that, on average, winters will become more climatically comfortable. What is missing from this assessment, however, is a nuanced understanding of the effects of extreme weather, such as cold surges, on hibernation tourism. Bringing gales, cooling, frost, and freezing rain, cold surges serve to reduce the effective temperature of the human body and thus our perception of climatic comfort (Wu et al., 2017a). Acknowledging the direct link between cold surges and human comfort, this paper has evaluated two widely used indices to provide a climatic perspective on the impacts of extreme weather on hibernation tourism. Our principal conclusions are as follows:

1. The correlation between the TCI and cold surge days is higher and more significant than that be tween the CCI and cold surge days. During our 1981-2010 study period, the TCI of Hainan and of Yuanjiang, Mengla, and Jinghong (Yunnan) all show significantly negative correlations (>95\% confidence) with cold surge days, whereby higher numbers of surge days per month result in lower TCI scores. The correlation between cold surge days and the CCI, however, is lower and not significant. We conclude, therefore, that the TCI is more effective for capturing the climatic influence of cold surges, due primarily to the higher temperature standards of that index and the preference for long sunshine hours. This finding was confirmed by Scott et al. (2016) and Hasanah et al. (2020), who both showed that the TCI yields the highest scores when sunshine hours are $>10$ hours.

2. Correlations between the CCI and TCI time series for the period 1981-2010 are not uniform among the various stations. The spatial difference between the CCI and TCI is most obvious in Yunnan, where the daily resolution of the CCI is more effective for analyzing daily comfort than is the monthly resolved TCI. As a result, various researchers have sought to improve the TCI and develop additional diurnal-scale indices, such as the CIT (de Freitas et al. 2004) and HCI (Scott et al. 2016). We propose that a direct comparison of these approaches will be a valuable contribution to our understanding of how cold surges impact hibernation tourism.

3. Correlations between the CCI and TCI and the Hainan tourist reception data for the period 20022010 in Hainan are poor, indicating that climatic comfort is not the sole factor affecting winter tourism. Other potential factors include government decision-making, economic development, infrastructure, and publicity. In their recent study of climatic comfort and visits to the Borobudur Temple, Indonesia, Hasanah et al. (2020) reported a correlation between TCI score and foreign visitations, although this correlation is not strong. In our study, we do not differentiate between foreign and domestic tourists. Hasanah et al. (2020) also showed that the HCI index returns higher correlations with both foreign and domestic tourist visitations.

4. In general, the island of Hainan is more climatically comfortable for hibernation tourists than Yunnan, as reported by Deng and Bao (2020). During the strong cold surge between 30 December 2004 and 2 January 2005, the drop in temperature on Hainan was less than that in Yunnan. We also note that the climatically optimal time for hibernation tourism is February in Yunnan and December-January on Hainan. Moreover, the cities of Mengla and Jinghong are the most comfortable locations for hibernation tourism in Yunnan, which is consistent with the study of Wu et al. (2017b). 


\section{Acknowledgements}

This research was supported by the Applied Basic Research Programs of Science and Technology Department of Yunnan Province (202101AT070161) and the National Natural Science Foundation of China (71864023 and 41561031) and is a contribution to the program for provincial innovative team of the climate change study of Greater Mekong Subregion (2019HC027). We thank the China Meteorological Administration for providing meteorological data. We appreciate two anonymous reviewers' comments and suggestions.

\section{References}

Chang, C.P., \& Lau, K.M.W. (1980). Northeasterly cold surges and near-equatorial disturbances over the winter MONEX area during December 1974. Part II: Planetary-scale aspects. Monthly Weather Review, 108, 298-312.

Chang, C.P., Kuo, H.C., Lau, N.C., Johnson, R.H., Wang, B., \& Wheeler, M.C. (Eds.) (2011). The Global Monsoon System: Research and Forecast. (pp. 99110). World Scientific.

De Freitas, C.R. (1979). Human climates of northern China. Atmospheric Environment, 13(1), 71-77.

Ding, Y.H. (1990). A statistical study of winter monsoons in East Asia. Journal of Tropical Meteorolo$g y, 6(2), 119-128$.

Deng, L.Z., \& Bao, J.G. (2020). Spatial distribution of summer comfortable climate and winter comfortable climate in China and their differences. Geographical Research, 39(1), 41-52.

Feng, Q.L., \& Liang, J.F. (2010). Reflections on Wuzhou's sheltered tourism resources. China Economic and Trade Herald, 8, 71-71.

Huang, Y.C. (2016). Research on the Climatic Comfort of Cities in China's Cold Avoiding Destinations. Shanghai Normal University, 4-49.

Hasanah, N. A. I., Maryetnowati, D., Edelweis, F. N. \& et al. (2020). The climate comfort assessment for tourism purposes in Borobudur Temple Indonesia. Heliyon, 6(12), e05828.

Jin, A.Q., Zhang, A., \& Zhao, X.Y. (2019). Estimation of climate comfort in Eastern China in the context of climate change. Acta Scientiarum Naturalium Universitatis Pekinensis, 55(5), 887-898.

Lau, K. M., Chang, C.-P., \& Chan, P. H. (1983). Shortterm planetary-scale interaction over the tropics and midlatitudes. Part II: Winter-MONEX Period. Monthly Weather Review, 111, 1372-1388.

Lin, J.P., \& Guo, L.X. (2003). Evaluation of climate tourism resources for eleven tourism cities in southern China for sheltering from cold weather. Human Geography, 6, 26-30.

Lin, J.P., Chen, L.H., \& Xu, J. (2013). Opportunities of development for certain regions driven by consumers needs - Potentiality of winter resort tourism in
Xishuangbanna. Yunnan Geographic Environment Research, 25(1), 59-64.

Lin, J.P., Wang, H., Luo, Y.M, \& et al. (2019). Research on the Factors Influencing the Demand Driving Forces of the Chinese Elderly People in Cold Avoidance Tourism Consumption - Based on the "PushPull” Model Theory. Sustainable Development, 9(3), 485- 495.

Luo, S.Y., Chen, D.P., Chen, H.Y., \& Zhou, Y.P. (2017). Analysis and Evaluation of Tourism Climate Comfort in Zhanjiang City from 1986 to 2016. Journal of Lingnan Teachers College, 38(6), 147-153.

Mieczkowski, Z. (1985). The tourism climatic index: a method of evaluating world climates for tourism. Canadian Geographer, 29(3), 220-233.

Ma, L.J., \& Sun, G.N. (2009). Evaluation of climate comfort index for tourism hot-spot cities in west China. Arid Land Geography, 32(5), 791- 797.

Pullen, J., Gordon, A.L., Flatau, M., Doyle, J.D., Villanoy, C., \& Cabrera, O. (2015). Multiscale influences on extreme winter rainfall in the Philippines. Jouranl of Geophysical Research: Atmospheres, 120, 3292-3309.

Pang, B., \& Lu,R. (2019). Two distinct types of extratropical circulation anomalies associated with cold surges over the South China Sea. Journal of Climate, 32, 5069-5084.

Scott, D., Mcboyle, G., \& Schwartzentruber, M. (2004). Climate change and the distribution of climatic resources for tourism in North America. Climate Research, 27(2), 105-117.

Scott, D., Gossling, S., \& Hall, C. M. (2012). International tourism and climate change. Wiley Interdisciplinary Reviews. Climate Change, 3(3), 213-232.

Scott, D., Rutty,M., Amelung, B., \& Tang, M. (2016). An inter-comparison of the Holiday Climate Index (HCI) and the Tourism Climate Index (TCI) in Europe. Atmosphere, 7, 80.

Scott, D., Steiger, R., Rutty, M., Pons,M., \& Johnson, P. (2019). The differential futures of ski tourism in Ontario (Canada) under climate change: The limits of snowmaking adaptation. Current Issues in Tourism, 22(11), 1327-1342. 
Scott, D., Steiger,R., Dannevig, H., \& Aall, C. (2020). Climate change and the future of the Norwegian alpine ski industry. Current Issues in Tourism, 23(19), 2396-2409.

Steiger, R., \& Stötter, J. (2013). Climate change impact assessment of ski tourism in Tyrol. Tourism Geographies, 15(4), 577-600.

Steiger, R., Scott, D., Abegg, B., Pons,M., \& Aall, C. (2019). A critical review of climate change risk for ski tourism. Current Issues in Tourism, 22(11), 1343-1379.

Steiger, R., \& Scott, D. (2020). Ski tourism in a warmer world: Increased adaptation and regional economic impacts in Austria. Tourism Management, 77, 104032.

Shi, Z.Y. (2016). Research on the Temporal and Spatial Distribution Characteristics of Tourism Climate Comfort in Gansu Province. Geography Teaching, 8, 7-11.

Thom, E. C. (1959). The discomfort index. Weatherwise, 12(2), 57-61.

Terjung, W.H. (1966). Physiologic Climates of the Conterminous United States: A Bioclimatic Classification Based on Man. Annals of the Association of American Geographers, 56(1), 141-179.

Xu, D.H., \& Zhu, R. (2000). Analysis and research on human perception of temperature, humidity, wind speed and clothing index. Chinese Journal of Applied Meteorology, 4, 430-439.

Xia, Z.L., Xie, H.Y., Huang, C.X., \& Chen, Q.Q. (2018). Evaluation and analysis of climate sheltered areas in Chishui City. Meteorological and Meteorological Lattices, 42(1), 77-80.

Xie, M., Sun, M., Liao, X.P, Li, Y.L, \& Li, Y.J. (2019). Guangxi Mashan Tourism Climate Resource Eval- uation. Meteorological Research and Application, 40(2), 80-85.

Xin, Y.Y., \& Li, B. (2019). Guide County Tourism Climate Comfort Evaluation. Qinghai Meteorology, 2, 91-94.

Yu, G., Schwartz, Z., \& Walsh, J. E. (2009). A weatherresolving index for assessing the impact of climate change on tourism related climate resources. Climatic Change, 95(3), 551-573.

Yu, Z. K., Sun, G. N., Luo, Z. W., \& Feng, Q. (2015). An analysis of climate comfort degree and tourism potential power of cities in Northern China in summer to the north of $40 \mathrm{~N}$. Journal of Natural Resources, 30(2), 327-339.

Yu, Z.Y., \& Li, A.P. (2018). Analysis on the tourism climate comfort in Pingliang City. Journal of Tianshui Normal University, 38(2), 84-87.

Zhao, S.X. \& Zeng, Q.C. (2005). A study of East Asia strong cold wave-surge crossing equator and influencing the development of tropical cyclone and heavy rainfall in the Southern Hemisphere. Climatic and Environmental Research, 10(3), 507-525.

Zhang, S.P., \& Lin, H. (2020). Evaluation research on the environmental comfort of Chinese major tourism cities. Geographical Science Research, 9(4), 215222.

Wu, J., Gao, X., Giorgi, F., \& Chen, D. (2017a). Changes of effective temperature and cold/hot days in late decades over China based on a high resolution gridded observation dataset. International Journal of Climatology, 37, 788-800.

Wu, J., Gao, X., Han, Z., \& Xu, Y. (2017b). Analysis of the Change of Comfort Index over Yunnan Province Based on Effective Temperature. Advances in Earth Science, 32(2), 174-186. 